\title{
Bad Times and the Political Behavior of Older African-Americans
}

Steven A. Peterson, Alfred University

Albert Somit, Southern Illinois University, Carbondale

This essay explores the effects of two specific life experiences upon the political attitudes and behavior of older African-Americans as compared with younger African-Americans. The findings that emerge are generally opposite what theory would predict. Poorer health and experiencing traumatic events seem to increase, by direct and indirect routes, the likelihood of African-Americans becoming more active in politics. Possible explanations for the unexpected findings are discussed.

We know a considerable amount about the political behavior of black Americans. We know much less, though, about the political behavior of older black Americans (see Peterson and Somit 1992a, 1992b). And we know even less about how life experiences help to shape the political behavior of older blacks. This becomes especially important given the number of black older Americans, for, as Green and Siegler remind us, "Over the last decade, the elderly black population age 65 and over has had a larger increase than either the elderly white or the young black population" (1984, 221; also see Longino 1988; Torres-Gil 1992; Myers 1990).

In this essay, we explore the possible influence of life experience variables on the political behavior of older black Americans. The specific factors that we consider are health status and stress. Both, to anticipate the immediately following theoretical discussion, would be expected to have substantial effects on the political behavior of mature black citizens. Our actual results, though, leave us with a puzzle.

\section{Theory and Hypotheses}

\section{Health Status}

At a theoretical level, speaking of the total adult population rather than of just older blacks, there are at least two reasons why health status might be politically relevant. First, those who are seriously ill or chronically

Steven A. Peterson is Professor of Political Science at Alfred University.

ALBERT SOMIT is Distinguished Service Professor of Political Science at Southern Illinois University. Carbondale. 
incapacitated are manifestly less able to engage in "outside" activities. Second, those who are ill may adopt a "sickness role" (Sanders 1982; Parsons 1951; Mechanic 1965), in which they are considered exempt from normal civic as well as personal obligations, including, we might speculate, political involvement. Illness frequently results in greater passivity, increased sense of helplessness, and reduced social functioning. Being sick lowers one's sense of competence and well-being (Mechanic and Hansell 1987). For many people, this could have political consequences, among which would be less interest in politics, a lowered sense of political efficacy, and, ultimately, diminished likelihood of participating in a broad array of political activities.

There is abundant evidence to support the theory. David Schwartz (1976a, 1976b, 1978; Schwartz et al. 1975) has conducted several studies of the relationship between health and political activity, using a national adult sample, high school students in New Jersey, adults in the urban northeast, members of Congress, top-level administrators in Washington, D.C., and federal appeals court judges. He finds that poorer health is associated with depressed levels of participation, more negative views toward the political world, and more passive views toward politics (also see Peterson 1988, but cf. Booth and Welch 1976; McBride 1980). National Opinion Research Center data from 1982 and 1984 show that healthier people are somewhat less alienated from politics, somewhat more conservative, and more interested in politics, even though the associations are very modest (Peterson 1988, 1990). Data from 1987 suggest that better health translates into more politically active citizens (Peterson 1991).

There has been some research on the relationship between health status and the political views of older Americans. Although one inquiry was limited to a sample of residents of a rural, upstate New York county-hardly ideal for generalizing - the data show that as health declines, so, too, do political interest, efficacy, and participation (Peterson 1987). Poor health has also been found to be associated with less conservative orientations (Peterson 1989, 1990), perhaps an indication that those with greater needs are more supportive of government assistance. Another study suggests that better health status predicts greater likelihood of voting among older whites-but not older blacks (Bazargan, Kang, and Bazargan 1991; Bazargan, Barbre, and Torres-Gil 1992).

We know, too, that the health of older blacks is poorer than among their white peers. According to Greene and Siegler $(1984,226)$ :

. elderly blacks experience higher mortality rates from chronic diseases and greater limitations of activities due to chronic conditions. . [B]lacks have particularly high mortality rates in the circulatory disease categories. These findings are consistent with 
descriptive self-report data from a current nationally representative sample of black adults $\mathbf{5 5}$ and older who report moderate to high levels of physical health problems and high incidence of such chronic health problems as hypertension. arthritis, and rheumatism.

Previous research strongly indicates a linkage between health status and politicization. This is our focus. It is an important issue, since there is evidence that political activism can affect public officials' decisions (e.g., Verba and Nie 1972). Given this literature (e.g., Schwartz 1976a, 1976b, 1978; Schwartz et al. 1975; Peterson 1988, 1990), we hypothesize that:

\section{Better health among older African Americans will be associated with greater politicization.}

Stress

Stress is a second biosocial variable that could have measurable political effects. Physiologically, stress is the body's response to demands made upon it (Selye 1982, 7). Stress itself is neither good nor bad; it is simply an aspect of our everyday lives. But, as Bloom, Lazerson, and Hofstadter put it $(1985,171)$ : "What is potentially harmful to animals, including human beings, is a prolonged period of stress or a combination of stressful events-called 'stressors' - that make it very difficult or impossible to adapt to the demands of the situation." Continued exposure to stressors can lead to physical illness (Dohrenwend and Dohrenwend 1974; House et al. 1979); experiments with primates indicate that stressful situations-if prolongedproduce ulcers and atherosclerosis (Bloom, Lazerson, and Hofstadter 1985, 171-174). Zegans declares that cognitive and affective responses to stress ". . . can alter the functioning of those vital hypothalamic-pituitary pathways that modulate endocrine, autonomic, and immune responses. Alteration of these systems and of the brain sets the stage for the onset of disease" (1982, 150).

Stress also may have psychological effects, such as alienation (Manderscheid, Silbergeld, and Dager 1975), depression (Nezu and Ronan 1985), and anxiety (Cohen, Kamarck, and Mermelstein 1983). Stressors can lead to withdrawal and passivity and may engender "learned helplessness" (Seligman 1975). Some people, of course, are better able to cope with stress than others, via such mechanisms as problem-solving ability (Nezu and Ronan 1985) and social support (e.g., Lin et al. 1979; Wethington and Kessler 1986). There is also some indirect evidence that an individual's ability to respond to or successfully cope with stress may have a genetic basis (Farber 1982). 
Coming closer to our concerns here, stress also has consequences for political behavior. Two scholars report that serious personal problems tend to have depoliticizing consequences (Brody and Sniderman 1977. See also Rosenstone 1982). The stressful belief that one's economic fortunes are declining is associated with increased alienation and, perhaps, a serious decline in support for the political system (Ostheimer and Ritt 1982). Another inquiry found that personal trauma correlated with increased liberalism and greater anomie (Peterson 1990).

Are there any data about the influence of stress on political behavior among the elderly in particular? The only study with which we are familiar is based upon a rural sample of older Americans from upstate New York. Here, a summed index of personal problems (the operational definition of stress) was found to be associated with reduced political interest, efficacy, and participation (Peterson 1990). However, the sample was too limited to permit any generalizations.

Our basic hypothesis for stress, then, is:

Greater stress among elderly African-Americans will be associated with reduced politicization.

However, Greene and Siegler suggest that the actual impact of stress might not be so clearcut. They note that: "When one has lived with stress and few economic resources and assets throughout a lifetime, negative outcomes in late life may appear less serious, or one may have developed a reliable set of strategies for coping with transitions" $(1984,227)$. For this reason, they continue, "It has been suggested that blacks, because of their unique history, react differently in life crises" $(1984,228)$. Older blacks, then, may cope better with stress-including more health problems-than whites and, hence, manifest fewer and weaker effects of both stress and health status on their political orientations and behavior (Markides, Liang, and Jackson 1990). In addition, the extended family of elderly blacks may well be an available source of support to help cope with stressful problems (see e.g., Taylor 1985; Markides, Liang, and Jackson 1990). Indeed, our data allow us to see the extent to which Greene and Siegler's argument is supported by the evidence.

\section{Methods}

The 1987 National Opinion Research Center (NORC) General Social Survey (GSS) included a black oversample. All told, 544 blacks were interviewed that year. There are 157 black respondents 55 years of age and 
older. We compare older African-Americans with those who are younger, using the entire black oversample in the process. ${ }^{1}$ We selected 55 as the cutoff point for two reasons, one practical and one theoretical. First, 55 gives us a larger sample size than does 65 -and we are dealing with rather small numbers as it is. Second, other literature frequently has used 55 as a cutoff point (e.g., Berelson, Lazarsfeld, and McPhee 1954; Campbell 1979). In addition, those 55 and over, sometimes categorized as "near-old," very often have interests and concerns similar to those who are 65 or more (e.g., see Peterson and Somit 1990).

\section{Independent Variables}

Health status. Two items on the 1987 NORC survey assay health status. These ask: (1) "Would you say your own health, in general, is excellent, good, fair, or poor?" and (2) ". . . how much satisfaction [do] you get from your health and physical condition [a very great deal, a great deal, quite a bit, a fair amount, some, a little, none]." On self-perceived health status, 12 percent rated themselves as excellent, 38 percent as good, 37 percent as fair, and 13 percent as poor. On the second question, 8 percent rated themselves as satisfied a very great deal and 27 percent a great deal. About 35 percent of the respondents, then, classify themselves as pleased by their health status. Nineteen percent say that they are satisfied quite a bit, 20 percent a fair amount, 8 percent some, 11 percent a little, and 5 percent not at all.

We then created a summed index. Respondents were given one point if they said that their health was either very good or good; another point was awarded to those who said that they were satisfied a very great deal or a great deal with their health. A score of 2 , therefore, represents a (selfperceived) high level of health, and a score of 0 represents relatively poor health. Sixty-three percent attained a score of $0 ; 28$ percent scored at 1 ; only 9 percent had two points (signifying good health). These scores run somewhat lower than those for older white respondents (Peterson and Somit 1990).

Needless to say, there are problems with self-reports of health (see, e.g., Kobassa 1982; Wolinsky 1980; Brunswick 1977; Glandon, Counte, and Tancredi 1992). But there is abundant evidence that self-reports can be both reliable and valid metrics of health status, and that self-assessments are positively associated with physicians' diagnoses, medical record data, differential mortality, presence of chronic conditions, and the use of doctors (e.g., see Garrity 1978; Fillenbaum 1979; Ware 1986; Ferraro 1980; Kaplan, Barell, and Lusky 1988; Idler and Kasl 1991; Rodin and McAvay 
1992; Wolinsky and Johnson 1992; Sherbourne and Meredith 1992; Siu et al. 1993). Although self-ratings-including global "feeling state" (the term comes from Baumann 1961)-are sometimes criticized as too subjective, unreliable, and invalid, the results seem to speak otherwise (Ware 1986). Among the elderly, we should add, there are a couple of complicating factors: Ferraro (1980) points out that those aged 75 and over tend to be more positive in their health ratings than those from 65 to 74; also, ceteris paribus, males tend to report better health than females. These are two selfreport anomalies of which readers need be aware.

The two-item index created to stand for health status has decent reliability. Cronbach's alpha is .60 (standardized item alpha $=.68$ ). The Pearson's correlation coefficient between the two health measures is a robust .51 .

Is the index valid? Construct validity (about which, see Carmines and Zeller 1979), that is, how the scale actually "performs" in data analysis, may be our best starting point. The obvious query is whether the results are what they ought to be in light of theory and prior research. By this criterion, the two-item index behaves as if it were indeed valid; it is affected by socioeconomic factors as it should be (respondents with more education and higher incomes tend to report being healthier), and it predicts political orientations and behavior as expected.

Stressful experiences. The NORC survey includes measures of traumatic, i.e. stressful, events that individuals report having experienced over the past five years. A summed index was created by NORC to represent the total number of such events. Stressors encompassed by this index are: divorces, unemployment episodes, hospitalizations, disabilities, and deaths of those close to the individual (e.g., parents, siblings, spouses, children). Each of these has been adjudged very stressful by experts (e.g., compare with Holmes and Rahe 1967). While health-related problems are a part of this measure, the correlation between health status and traumas is low (-.08 among older African-Americans and a modest but not overwhelming - .15 for younger blacks).

\section{Dependent Variables}

Several instruments serve to register level of politicization. One asked whether respondents were ". . interested in politics and national affairs. ..." Since information level is a related aspect of politicization, the NORC survey also asked if the interviewees could name their governor, member of Congress, and the head of their local school board. An index was formed to reflect amount of political information: if a respondent knew all three 
names, that person would receive a score of 3; if he or she knew none of these figures, the score would be 0 (Cronbach's alpha $=.64$; standardized item alpha $=.64$ ).

Finally, we used an index of political participation based on the Verba and Nie (1972) questions where, regrettably, no items ascertaining participation in "non-traditional" forms of political behavior (e.g., protest participation) were included. People were asked whether or not-and to what extent-they participated in the following: "worked with others in the community to try to solve some community problem," "taken part in forming a new group or a new organization to try to solve some community problems, " "try to show people why they should vote for one of the parties or candidates," "work for one of the parties or candidates," "attended any political meetings or rallies, " "gone to see, or spoken to, or written to some member of local government," "contacted or written. . .some representatives or government officials outside of the local community," "contributed money to a political party or candidate or to any other political cause," vote regularly in local elections, voted in the 1984 presidential election. If a respondent reported contacting a public official either at the local level or outside the community, that interviewee was then asked if the contact was about a community problem or about a problem particular to him or her. A summed index was created, indicating the number of different activities carried out. Cronbach's alpha is .74 (standardized item alpha $=.75$ ).

\section{Findings}

Results speaking to our hypotheses are presented in Table 1. We conducted multiple regression (listwise) analysis to determine the relationship between health and stress, on the one hand, and political orientations and behavior, on the other, while controlling for the effects of age, sex, education, and group memberships. We did this for both older and younger African-Americans. Health status and stress seem only slightly associated with politicization. Tables 1 and 2 report both the betas (standardized regression coefficients) and the unstandardized regression coefficients (the latter provides for a comparison between the two cohorts of the impact of each independent variable on the dependent variables).

Better health among older blacks is related to less political interest $(\mathrm{P}<.10)$; among younger blacks, it is not linked with any metric of politicization. One interesting comparison, though, is the direction of the relationship in older versus younger blacks (note the unstandardized regression coefficients). Better health leads to less interest among older AfricanAmericans and it is non-statistically but interestingly associated with interest 
Table 1. Health Status as Predictor of Politicization

\begin{tabular}{lcccc}
\hline & \multicolumn{4}{c}{ Health Status } \\
& \multicolumn{2}{c}{$\begin{array}{c}\text { Older Blacks } \\
(\mathrm{N}=124)\end{array}$} & $\begin{array}{c}\text { Younger Blacks } \\
(\mathrm{N}=328)\end{array}$ \\
Politicization & $\mathrm{b}$ & Beta & $\mathrm{b}$ & Beta \\
\hline & & & & .05 \\
Interest in politics & -.23 & $-.16 *$ & .07 & -.02 \\
Information level & -.06 & -.04 & -.03 & .01 \\
Follow news regularly & .20 & .08 & .02 & .01 \\
Political participation & -.18 & -.05 & .04 & \\
$* \mathrm{P}<.10$ & & & & \\
\hline
\end{tabular}

in a positive direction among younger African-Americans. Not to overinterpret findings, it does appear that health's impact on political interest is specified by age among black Americans. The second stage of data analysis, reported in Table 2, entails the analysis of the effects of traumatic events on politicization. Among our older cohort, greater experienced trauma is associated with higher levels of political participation with controls in place. This relationship does not obtain for the younger blacks. However, the latter cohort does show a linkage between experiencing traumata and greater interest in politics. Findings for both older and younger African-Americans are precisely contrary to our predictions.

\section{Table 2. Traumatic Events as Predictor of Politicization}

\begin{tabular}{lcccc}
\hline & \multicolumn{4}{c}{ Traumatic Events } \\
& \multicolumn{2}{c}{$\begin{array}{c}\text { Older Blacks } \\
(\mathrm{N}=121)\end{array}$} & $\begin{array}{c}\text { Younger Blacks } \\
(\mathrm{N}=328)\end{array}$ \\
Politicization & $\mathrm{b}$ & Beta & $\mathrm{b}$ & Beta \\
\hline Interest in politics & & & .13 & $.13 *$ \\
Information level & .01 & .00 & .07 & .07 \\
Follow news regularly & .00 & .00 & .07 & .03 \\
Political participation & -.01 & .00 & .03 & .05 \\
$* \mathrm{P}<.05$ & .47 & $.18 *$ & .12 & \\
\hline
\end{tabular}


Next, we report the outcomes of two path analyses exploring the impact of health status and experiencing traumatic events on political activism among both older and younger African-Americans. Figure 1 describes the pathways from health status and traumatic events to political participation. We used stepwise regression and made the following assumptions: political interest, age, sex, education, health status, traumatic events, and group memberships will bear upon level of participation; political interest will be shaped by age, sex, education, group involvement, traumas experienced, and health status. Group memberships, we assume, will be influenced by age, sex, education level, health status, and traumatic events experienced. Finally, we anticipate that health status and experiencing traumas will be influenced by age, sex, and education.

Figure 1a focuses on the older cohort. The Multiple $\mathrm{R}$ is a robust .72; the variables that have a direct pathway to participation (education, political interest, traumatic experiences, and group memberships) explain 52 percent of the variation in older African-Americans' level of political participation. For our purposes, the key finding is a direct pathway from traumatic experiences to activism. And health status has an indirect role, as well. Healthier older blacks are less interested in politics (leading thereby to a slight reduction in participation), although more involved in groups (in this manner, having an indirect effect upon elevating levels of participation).

Figure $1 \mathrm{~b}$ repeats the process-this time with younger blacks as the focal point of analysis. Assumptions are the same as with Figure 1a. Health drops out of the picture for this cohort. However, experiencing traumatic events is tied to increased political interest and, as a result, indirectly increases political activism. Again, this is quite different from what we had expected.

\section{Summary and Discussion}

The first impression from our findings is that, for both older and younger blacks, according to results from multiple regression analysis, there are only weak ties linking stress, health, and politicization. Null findings abound in Table 1. More puzzling still, the few relationships that do emerge as noteworthy are contrary to what theory and commonsense suggest - that greater stress among older blacks leads to more political activism and among younger African-Americans to greater political interest. Better health goes with less interest in politics among older blacks.

Prior research on adults in general, and on elderly Americans in particular, yielded quite different results: poorer health status was consistently associated with depoliticization (Peterson 1991; Peterson and Somit 1990). 
Figure 1. Arrow Diagram: Health Status, Traumatic Events, and Political Participation

a. Older African-Americans $(\mathrm{N}=134)$

Age

$\downarrow .18(.03)$

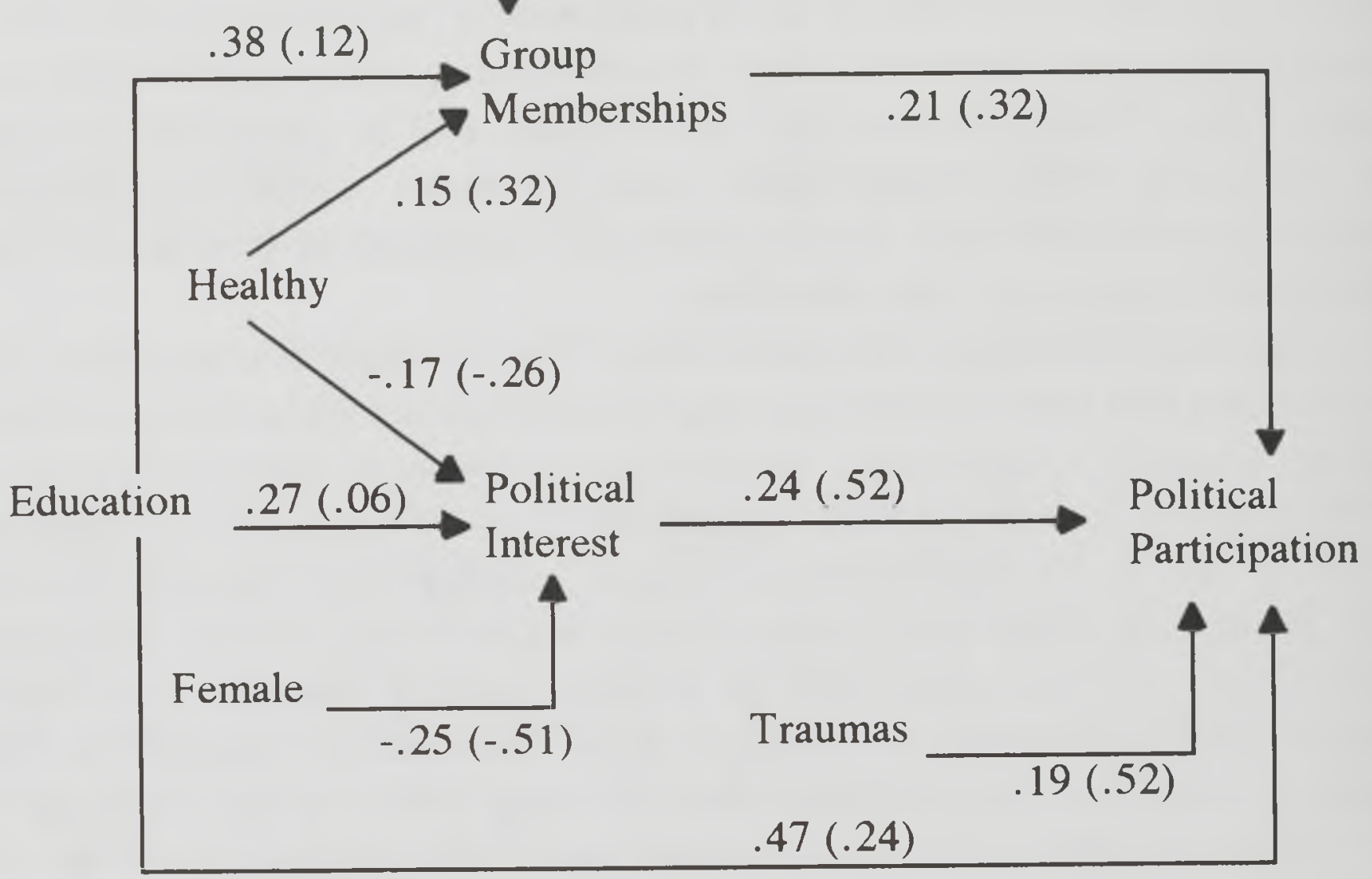

b. Younger African Americans $(\mathrm{N}=349)$

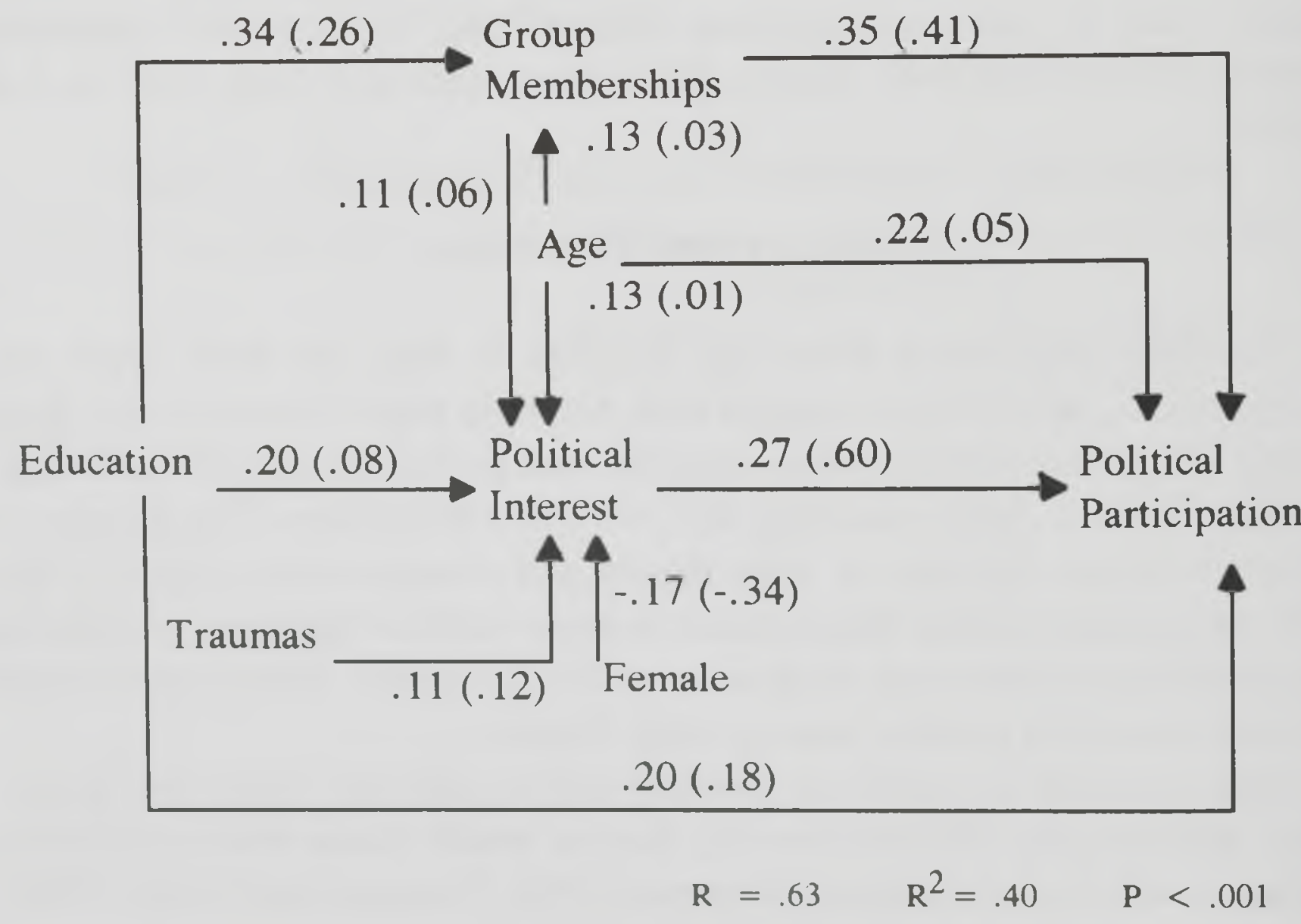


What might account for the strange findings among African-Americans? One possibility is the contention that because of harsher life experiences over time, older blacks (and apparently younger African-Americans as well) are better able to cope with health problems and stresses than are older white citizens. If so, we would expect the otherwise negative impacts of health status (and presumably stress; see, e.g., Peterson 1990) to weaken greatly or even disappear. The host of nonsignificant findings then would not surprise us.

That raises another, more troublesome question: what of the unexpected findings with respect to political interest and participation? The easy way out might be to claim that these are simply meaningless results, chance statistical findings (after all, of the correlations that we examine, some will attain statistical significance by chance alone). But it would be a remarkable coincidence if this were true, for both independent variables-despite their ineffective performance as predictors overall-end up having effects on political participation (one has direct effects and the other indirect, according to our path analyses).

Is it conceivable that Harold Lasswell's venerable formulation, although intended to explain elite recruitment, may be relevant here? He suggested that the political person-a member of the political elite-is one who displaces private motives onto public objects, arguing that $(1948,39) "$. . . power is expected to overcome low estimates of the self." And poor health, said Lasswell, can cause low self-esteem. Thus, older blacks (and younger African-Americans as well), as one consequence of their life experiences, actually may become more motivated to take part in politics. As others have found, if people blame the political establishment for their problems, they may become more active rather than being depoliticized (Brody and Sniderman 1977; Sniderman and Brody 1977).

\section{NOTES}

'It would be ideal to compare results over time, using a cohort analysis to tease out any lifecycle versus generational effects. However, the 1987 NORC survey is the only source we could find that included all of the appropriate variables. Thus, we must content ourselves with this one-shot survey approach.

\section{REFERENCES}

Bazargan. Mohsen. Ann R. Barbre, and Fernando Torres-Gil. 1992. Voting Behavior among Lowincome Black Elderly. The Gerontologist 32: 584-591. 
Bazargan, Mohsen, Tai S. Kang, and Shahrzad Bazargan. 1991. A Multi-variate Comparison of Elderly African Americans and Caucasian Voting Behavior. International Joumal of Aging and Human Development 32: 181-198.

Bloom, Floyd E., Arlyne Lazerson, and Laura Hofstadter. 1985. Brain, Mind, and Behavior. New York: Freeman.

Booth, Alan, and Susan Welch. 1976. Stress, Health, and Political Participation. Presented at annual meeting of the International Political Science Association, Edinburgh, Scotland.

Brody, Richard, and Paul M. Sniderman. 1977. From Life Space to Polling Place. British Joumal of Political Science 7: 337-360.

Brunswick, A.F. 1977. Indicators of Health Status in Adolescents. In J. Elinson and A.E. Siegmann, eds., Socio-Medical Indicator. Farmingdale, NY: Baywood Publishing Company.

Carmines, Edward G., and Richard A. Zeller. 1979. Reliability and Validity Assessment. Beverly Hills: Sage.

Cohen, Sheldon, Tom Kamarck, and Robin Mermelstein. 1983. A Global Measure of Perceived Stress. Journal of Health and Social Behavior 24: 385-396.

Dohrenwend, Barbara Snell, and Bruce P. Dohrenwend, eds. 1974. Stressful Life Events. New York: John Wiley.

Farber, Susan L. 1982. Genetic Diversity and Differing Reactions to Stress. In Leo Goldberger and Shlomo Breznitz, eds.. Handbook of Stress. New York: Free Press.

Ferraro, Kenneth F. 1980. Self-ratings of Health among the Old and the Old-old. Journal of Health and Social Behavior 21 : 377-383.

Fillenbaum, G.G. 1979. Social Context and Self-assessments of Health among the Elderly. Journal of Health and Social Behavior 20: 45-51.

Garrity, T.F. 1978. Factors Influencing Self-assessments of Health. Social Science and Medicine 12: 77-81.

Glandon, Gerald L., Michael A. Counte, and Daniel Tancredi. 1992. An Analysis of Physician Utilization by Elderly Persons: Systematic Differences between Self-report and Archival Information. Journal of Gerontology 47: S245-S252.

Goldberger, Leo, and Shlomo Breznitz, eds. 1982. Handbook of Stress. New York: Free Press.

Greene, R.L., and I.C. Siegler. 1984. Blacks. In Erdman B. Palmore, eds. Handbook of the Aged in the United States. Westport, CT: Greenwood Press.

Holmes, Thomas N., and Richard H. Rahe. 1967. The Social Readjustment Rating Scale. Journal of Psychometric Research 11: 213-218.

Holzberg, Carol S. 1982a. Ethnicity and Aging: Anthropological Perspectives on More than just the Minority Elderly. The Gerontologist 22: 249-2.57.

1982b. Ethnicity and Aging: Rejoinder to a Comment by Kyriakos S. Markides. The Gerontologist 22: 471-472.

House, James S., et al. 1979. Occupational Stress and Health among Factory Workers. Joumal of Health and Social Behavior 20: 139-160.

Idler, E.L., and S. Kasl. 1991. Health Perceptions and Survival. Journal of Gerontology 46: S55-S65

Kaplan, G., V. Barell, and A. Lusky. 1988. Subjective State of Health and Survival in Elderly Adults. Journal of Gerontology 43: S114-S120.

Kobassa, Suzanne C. 1982. The Hardy Personality. In G. S. Sanders and J. Suls, eds., Social Psychology of Health and Illness. Hillsdale, NJ: Lawrence Erlbaum Associates.

Lasswell, Harold D. 1948. Power and Personality. New York: Viking Edition.

Lin, Nan, et al. 1979. Social Support. Stressful Life Events, and Illness. Journal of Health and Social Behavior 20: 108-119.

Longino, Charles F. 1988. Who Are the Oldest Americans? The Gerontologist 28: 515-523.

McBride, Alan. 1980. Health and Body Image: Effect on Socialization. Paper presented at annual meeting of the Midwest Political Science Association. Chicago, IL.

Markides. Kyriakos S. 1982. Ethnicity and Aging: A Comment. The Gerontologist 22: 467-470. 
Jersey Liang. and James S. Jackson. 1990. Race. Ethnicity, and Aging: Conceptual and Methodological Issues. In Robert H. Binstock and Linda K. George, eds., Handbook of Aging and the Social Sciences, third edition. New York: Academic Press.

Mechanic. David. 1968. Medical Sociology. New York: The Free Press.

and S. Hansell. 1987. Adolescent Competence. Psychological Well-being, and Selfassessed Physical Health. Journal of Health and Social Behavior 28: 364-374.

Myers, George C. 1990. Demography of Aging. In Robert H. Binstock and Linda K. George. eds.. Handbook of Aging and the Social Sciences, third edition. New York: Academic Press.

Nezu. Arthur M., and George F. Ronan. 1985. Life Stress, Current Problems. Problem Solving. and Depressive Symptoms. Journal of Consulting and Clinical Psychology 53: 213-218.

Ostheimer, John M., and Leonard G. Ritt. 1982. Abundance and American Democracy. Journal of Politics 44: 365-387.

Parsons. Talcott. 1951. The Social System. New York: Free Press.

Peterson. Steven A. 1987. Biosocial Predictors of Older Americans' Political Participation. Politics and the Life Sciences 5: 246-251.

1988. Health and the Polity. Paper presented at annual meeting of the International Political Science Association, Washington, D. C.

1989. Health Status, Energy Level, and Political Behavior among the Elderly: A Rural Case Study. Paper presented at annual meeting of the American Political Science Association. Atlanta, GA.

1990. Political Behavior: Patterns in Everyday Life. Newbury Park. CA: Sage.

1991. The Health of the Polity: Results from a National Sample. Politics and the Lfe Sciences 10: 45-56.

and Albert Somit. 1990. Older Americans' Health Status and Their Political Behavior: Implications for the Future? Paper presented at meeting of the Animal Behavior Society. Binghamton, NY.

1992a. The Political Behavior of American Blacks: A Research Note on Three Contending Theories. Paper presented at annual meeting of the American Political Science Association, Chicago, IL. $592-600$.

1992b. The Political Behavior of Older American Blacks. The Gerontologist 32:

Rodin, Judith, and Gail McAvay. 1992. Determinants of Change in Perceived Health in a Longitudinal Study of Older Americans. Journal of Gerontology 47: P373-P384.

Rosenstone, Steven J. 1982. Economic Adversity and Voter Turnout. American Journal of Political Science 26: 25-46.

Sanders, G.S. 1982. Social Comparison and Perceptions of Health and Illness. In G. S. Sanders and J. Suls, eds., Social Psychology of Health and Illness. Hillsdale, NJ: Lawrence Erlbaum.

Schlozman, Kay Lehman, and Sidney Verba. 1979. Injury to Insult. Cambridge: Harvard University Press.

Schwartz. David C. 1976a. The Influence of Health Status on Basic Attitudes in an American Political Elite. Paper presented at annual meeting of the International Political Science Association. Edinburgh, UK.

1976b. Somatic States and Political Behavior. In Albert Somit, ed., Biology and Politics. Paris: Mouton.

1978. Health Status, Self-image, and Political Behavior in America's Governmental Elite. Paper presented at annual meeting of the Western Political Science Association, Los Angeles, CA.

. Joseph Garrison, and James Alou. 1975. Health. Body Images, and Political Socialization. In David C. Schwartz and Sandra Kenyon Schwartz, eds., New Directions in Political Socialization. New York: Free Press.

Seligman, M.E.P. 1975. On Depression, Development, and Death. San Francisco: Freeman. 
Selye, Hans. 1982. History and Present Status of the Stress Concept. In Leo Goldberger and Shlomo Breznitz, eds., Handbook of Stress. New York: Free Press.

Sherbourne, Cathy Donald, and Lisa S. Meredith. 1992. Quality of Self-report Data. Journal of Gerontology 47: S204-S211.

Siu, Albert L., Ron D. Hays, Joseph G. Ouslander, Daniel Osterwell, R. Burciaga Valdez. Michelle Krynski, and Amy Gross. 1993. Measuring Functioning and Health in the Very Old. Journal of Gerontology 48: M10-M14.

Sniderman, Paul M., and Richard Brody. 1977. Coping: The Ethic of Self-reliance. American Journal of Political Science 21: 501-522.

Taylor, R.J. 1985. The Extended Family as a Source of Support for Elderly Blacks. The Gerontologist $25: 488-495$.

Torres-Gil, Fernando. 1992. The New Aging. New York: Auburn House.

Verba, Sidney, and Norman H. Nie. 1972. Participation in America. New York: Harper and Row.

Ware, J.E., Jr. 1986. The Assessment of Health Status. In L. H. Aiken and David Mechanic, eds., Applications of Social Science to Clinical Medicine and Social Policy. New Brunswick, NJ: Rutgers University Press.

Wethington. Elaine, and Ronald C. Kessler. 1986. Perceived Support, Received Support. and Adjustment to Stressful Life Events. Journal of Health and Social Behavior 27: 78-89.

Wolinsky, Frederic D. 1980. The Sociology of Health. Boston: Little, Brown.

and Robert J. Johnson. 1992. Perceived Health Status and Mortality among Older Men and Women. Journal of Gerontology 47: S304-S312.

Zegans, Leonard. 1982. Stress and the Development of Somatic Disorders. In Leo Goldberger and Shlomo Breznitz, eds., Handbook of Stress. New York: Free Press. 